\title{
To Evaluate Results of Operative Management of Tibial Plateau Fractures
}

\author{
Shaikh Naeem ul Haq, Syed Salman Adil, Raza Askari
}

\begin{abstract}
OBJECTIVE: To evaluate the result of open reduction and internal fixation in tibial plateau fractures in accordance with Rasmussen's criteria of knee pain, range of motion and stability.

METHODS: Ninety two patients of tibial plateau fractures of either sex between 20-60 years of age participated in this study. We used open reduction and internal fixation in patients depending on Schatzker's tibial plateau fractures classification. This study was conducted during June 2014 to June 2015 at Dow University Hospital (DUH), Civil Hospital Karachi (CHK), Baqai Medical University Hospital (BMUH), Jinnah Post Graduate Medical Center (JPMC). Patients were followed for 6 months and outcome was compared with objective Rasmussen's criteria.

RESULTS: The results were established upon the type of fractures. Majority of the satisfactory results were in type-I, II, III and IV; however type-V and VI showed grave and poorer results. Overall range of motion of knee joint was more promising in type I, II, III and IV as compared to Type-V and VI. The results also depended upon the type of fracture.

CONCLUSION: Fractures of tibial plateau are affliction of a major weight bearing joint. In case the fracture is displaced with joint instability, treatment by open reduction and internal fixation with appropriate fixation devices is the treatment of choice. However, early knee range of motion exercises, quadriceps rehabilitation and delayed weight bearing are mandatory for a good final outcome.
\end{abstract}

KEYWORDS: Tibial plateau fractures, Open reduction and internal fixation, Rasmussen's criteria, Outcomes

This article may be cited as: Haq SN, Adil SS, Askari R. To Evaluate Results of Operative Management of Tibial Plateau Fractures. J Liaquat Uni Med Health Sci. 2017;16(03):135-8. doi: 10.22442/jlumhs.171630521

\section{INTRODUCTION}

The tibial plateau is a critical area which is prone to fracture particularly in elderly. Tibial plateau fracture causes morbidity and disability. Peak age is $30-40$ years in men and 60-70 in women. Approximately half of the patients who sustain tibial plateau fracture are aged over 50 year old ${ }^{1}$. Approximately one third of the tibial plateau fractures and more than half of fracture dislocations are associated with ligamentous injuries. Morbidity includes neurological and vascular insults, compartment syndrome, deep vein thrombosis, contusion or crush injury to the soft tissues. Surgical or non-surgical management depends on the degree of the fracture, patient's age and associated co-morbid and the involvement of soft tissues injuries ${ }^{2}$.

Optimal joint function depends on congruency, stability, correct load distribution and normal biologic quality of the cartilage. Restoration of these parameters is the therapeutic goal in all intra-articular fracture. Untreated ligamentous injuries result in poor function despite a well healed condylar fracture ${ }^{3,4}$. The aim of treating tibial plateau fractures is to obtain a stable, pain free knee with a range of motion that is satisfactory for functional requirement. Preferred treatment for tibial plateau fractures is open reduction and internal fixation in all displaced and unstable tibial plateau fractures ${ }^{5,6}$.

There had been many controversies in approaches while managing tibial plateau fracture ${ }^{7}$. Presently the standard treatment option is open reduction with anatomic restoration of articular surface. Outcome of treatment relies on extent of intra-articular comminution, the presence or absence of step-deformity on weight bearing surface, and residual angulation deformity.

Intra-articular comminution with depression conversely is more difficult problem. Even in cases where an accurate anatomic reduction is obtained, late collapse and deformity secondary to comminution on the weight bearing surface often preclude a good functional result. Open reduction and internal fixation can be used independently or in combination with external fixator but high rates of soft tissue damage and infectious complication have been reported ${ }^{8}$.

The advantages of open reduction and internal 
fixation include; the ability to recognize and repair associated meniscal and collateral ligament injuries, greater visualization of articular surface for restoration of joint congruence and avoidance of prolonged external fixation half-pins and wires which may cause infection $^{9,10}$.

The objective of this study was to evaluate the result of open reduction and internal fixation in tibial plateau fractures in accordance with Rasmussen's criteria of knee pain, knee extension, range of motion and stability.

\section{METHODOLOGY}

This study was conducted during June 2014 to June 2015 at Dow University Hospital (DUH), Civil Hospital Karachi (CHK), Baqai Medical University Hospital (BMUH), Jinnah Post Graduate Medical Center (JPMC) located in the city of Karachi, Pakistan. For this observational study convenience sampling was done. Inclusion criteria included all patients of tibial plateau fracture, with age 20-60 years, Isolated displaced tibial plateau fractures (Schatzker's classification), of either gender. The classifications of the fractures were according to the Schatzker's criteria. Before taking written consent all participants were informed regarding the nature and protocol of the study with reassurance of confidentiality of identity and personal information. Comprehensive medical history including complete clinical examination to detect any ligamentous, neurological and vascular injuries was done in all selected cases. $X$ ray of injured joint, CT scan in complex tibial plateau fractures were also part of pre operative protocol. Post -operatively, study subjects were assessed for the results according to using Rasmussen's criteria. The data was analyzed through statistical package for social sciences (SPSS) version 17, presented as mean, standard deviation and proportion for quantitative and qualitative variables.

Fractures were fixed with recommended internal fixation devices which included screw fixation for type I and locking plates for other types.

\section{RESULTS}

Overall we recruited 105 patients and 92 consented to participate in the study with a response rate of $88 \%$. Out of 92 participants 77 (84\%) were males and 15 $(16 \%)$ were females.

Among them, 59 (64\%) patients had a fracture on right knee while $33(36 \%)$ on the left knee. All patients were followed for six months. On each follow up visits patients were evaluated for pain, fracture healing, residual deformity, range of motion and functions by using Rasmussen's criteria (Table I). Results were classified as satisfactory, if the score was in category of excellent or good and unsatisfactory, if score was in range of fair or poor. The results found depended upon the types of fractures. Majority of the satisfactory results were in type-I, II, III and IV, while type-V and VI showed poor results. (Table II).

As motor cycle/bicycle is driven mostly by younger age group making this age group more vulnerable to road traffic accidents same was witnessed in current study where it was found most prevalent mode of injury $(60 \%)$, followed by automobile and pedestrian accidents ( $11 \%$ and $9.5 \%$ respectively). Other modes accounted for almost twenty percent of the cases (Table III).

In this study patients were evaluated for post operative complications like post operative wound infection, deep venous thrombosis (DVT), and implant failure. Among 21 patients who presented with Schatzer Type V and VI, 10 patients developed wound infection; probable explanation may be presumably more extensive tissue damage due to high energy trauma and more aggressive dissection during surgery as compared to other types. All these patients were treated with extended use of antibiotics and none needed any intervention. No DVT or implant failure was reported in first 6 months of follow-up.

\section{TABLE I: RAMUSSEN'S CRITERIA}

\begin{tabular}{|l|c|c|c|c|c|}
\hline \multicolumn{1}{|c|}{ Rating } & Pain & Walking Capacity & ROM & Clinical Signs & Stability \\
\hline Excellent & No & Normal & Normal & No & Normal \\
\hline Good & Minimal & $\begin{array}{c}\text { Walking outdoor for } \\
\text { at least } 1 \mathrm{hr}\end{array}$ & $75 \%$ of Normal & Swelling + & Minimal \\
\hline Fair & Occasional Ache & $\begin{array}{c}\text { Walking outdoor for } \\
15 \text { minutes }\end{array}$ & $>50 \%$ of Normal & Swelling ++ & $\begin{array}{c}\text { Instability in } \\
\text { flexion }\end{array}$ \\
\hline Poor & Pain at rest & Walking indoor only & $\begin{array}{c}50 \% \text { of normal } \\
\text { or less }\end{array}$ & Swelling +++ & $\begin{array}{c}\text { Instability in Flexion } \\
\text { as well as in } \\
\text { extension }\end{array}$ \\
\hline
\end{tabular}


Shaikh Naeem ul Haq, Syed Salman Adil, Raza Askari

TABLE II: CLASSIFICATION ACCORDING TO SCHATZKER'S (n=92)

\begin{tabular}{|l|c|c|c|c|c|}
\hline $\begin{array}{c}\text { Schatzker's } \\
\text { classification }\end{array}$ & $\begin{array}{c}\text { No. of } \\
\text { patients }\end{array}$ & Percentage & $\begin{array}{c}\text { 95\% confidential } \\
\text { interval }\end{array}$ & Knee ROM & $\begin{array}{c}\text { Mean } \\
\text { Rasmussen's }\end{array}$ \\
\hline Type-I & 28 & $30 \%$ & $13.6-50.4$ & $\begin{array}{l}19=\text { At least } 120^{\circ} \\
9=\text { At least } 90^{\circ}\end{array}$ & $\begin{array}{c}25 \\
\text { (Good-Excellent) }\end{array}$ \\
\hline Type-II & 24 & $26 \%$ & $12.4-42.2$ & $\begin{array}{l}11=\text { At least } 120^{\circ} \\
13=\text { At least } 90^{\circ}\end{array}$ & $\begin{array}{c}22 \\
\text { (Good-Excellent) }\end{array}$ \\
\hline Type-III & 10 & $11 \%$ & $6.2-23.5$ & $\begin{array}{l}6=\text { At least } 120^{\circ} \\
4=\text { At least } 90^{\circ}\end{array}$ & $\begin{array}{c}20 \\
\text { (Good-Excellent) }\end{array}$ \\
\hline Type-IV & 9 & $10 \%$ & $4.4-26.2$ & $\begin{array}{l}3=\text { At least } 120^{\circ} \\
6=\text { At least } 90^{\circ}\end{array}$ & $\begin{array}{c}18 \\
\text { (Good) }\end{array}$ \\
\hline Type-V & 13 & $14 \%$ & $3.4-16.8$ & $\begin{array}{l}5=\text { At least } 120^{\circ} \\
8=\text { At least } 90^{\circ}\end{array}$ & $\begin{array}{c}14 \\
\text { (Fair) }\end{array}$ \\
\hline Type-VI & 8 & $09 \%$ & $4.8-26.2$ & $\begin{array}{l}3=\text { At least } 120^{\circ} \\
5=\text { At least } 90^{\circ}\end{array}$ \\
(Fair)
\end{tabular}

TABLE III: MODE OF INJURY $(n=92)$

\begin{tabular}{|l|c|c|c|}
\hline Mode of injury & $\begin{array}{c}\text { No. of } \\
\text { patients }\end{array}$ & Percentage & $\begin{array}{c}95 \% \\
\text { confidential } \\
\text { interval }\end{array}$ \\
\hline $\begin{array}{l}\text { Motor cycle / } \\
\text { Bicycle }\end{array}$ & 55 & $60 \%$ & $46.4-82.6$ \\
\hline Automobile & 10 & $11 \%$ & $5.4-28.5$ \\
\hline Pedestrian & 9 & $9.5 \%$ & $4.6-31.8$ \\
\hline Miscellaneous & 18 & $19.5 \%$ & $12.2-27.8$ \\
\hline
\end{tabular}

\section{DISCUSSION}

Operative treatment methods when chosen in tibial plateau fractures, fixation must be stable enough to allow early knee motion and delayed weight bearing ${ }^{11}$. A cast is recommended when there are ligamentous injuries, when there is less than rigid fixation or when poor patient compliance is anticipated. Non-operative as well as operative procedure should reflect the standard while managing joint injuries. The most common treatment for displaced fractures of the tibial plateau has been open reduction with restoration of the articular surface to as near to the anatomical position as possible with internal fixation to maintain the reduction ${ }^{12-14}$.

Outcomes of the fracture of the medial condyle and in bicondylar fractures were found to be excellent in majority of the patients. Lubowitz $\mathrm{JH}$ divided 43 displaced tibial plateau fractures managed with open reduction and internal fixation into four groups ${ }^{15}$. The clinical results were evaluated by using standard 100point knee rating system. The average follow-up period after surgery was 2.7 years. Clinical results were excellent in 35 cases, five good in 5 , fair in 3 cases and no poor results. In above study the classification and scoring system used for evaluation is different from our study. The results of this study when compared with others; tibial plateau fracture are comparable to this study in terms of the number of the patient treated operatively and only one had a longer follow-up period and different to use evaluation criteria post-operatively. The unsatisfactory results in our series were seen in cases where ligamentous injuries were not identified and addressed intra-operatively and poor compliance by the patient, which may lead to decreased range of knee motion and instability. We restored the anatomy of all structures incised during the surgical approach, thus avoiding late morbidity. The open reduction and internal fixation shortened hospital stay, thus reducing the cost of treatment ${ }^{16,17}$. Long term outcome depends less on the reduction that is obtained and more on the stability of the knee and that less extensive operation may lead to satisfactory results. If the fracture is displaced or depressed with joint instability, open reduction and internal fixation with appropriate fixation devices is the treatment of choice. However, early knee range of motion exercises, quadriceps rehabilitation, and delayed weight bearing (i.e. after fracture union) are mandatory for a good final outcome ${ }^{18}$. Therefore while operating upon tibial plateau fractures guidelines should be followed such as stable internal fixation, careful elevation of the plateau along with sufficient subchondral bone and mechanical support 
underneath, early post-operative mobilization and range of motion exercises, anterolateral compartment fasciotomy in all cases of lateral buttressing plate, delayed weight bearing i.e. (after fracture union).

\section{CONCLUSION}

Fractures of the tibial plateau, are serious injuries of a major weight bearing joint, if the fracture is stable, joint is congruous and axial alignment is preserved then closed treatment of fracture is method of choice. Even with closed treatment early joint mobilization may be instituted.

\section{REFERENCES}

1. Kobbe P, Pape HC. Tibial Plateau Fractures. In Bone and Joint Injuries. 2014 (pp. 333-339). Springer Berlin Heidelberg.

2. Jiang R, Luo CF, Wang MC, Yang TY, Zeng BF. A comparative study of Less Invasive Stabilization System (LISS) fixation and two-incision double plating for the treatment of bicondylar tibial plateau fractures. Knee. 2008 Mar 31; 15(2):139-43.

3. Siegel J, Tornetta III P. Management of Complex Proximal Tibia Fractures (Schatzker Types $\mathrm{V}$ and VI). In Fractures Around the Knee 2016 (pp. 6375). Springer Cham.

4. Spagnolo $R$, Pace $F$. Management of the Schatzker VI fractures with lateral locked screw plating. Musculoskeletal Surg. 2012 Aug 1; 96 (2):75-80.

5. Jain RK, Shukla R, Baxi M, Agarwal U, Yadav S. Evaluation of functional outcome of tibial plateau fractures managed by different surgical modalities. Int J Res Orthop. 2016 Mar 21;2(1):5-12.

6. Brunner $A$, Honigmann $P$, Horisberger $M$, Babst $R$. Open reduction and fixation of medial Moore type II fractures of the tibial plateau by a direct dorsal approach. Arch Orthop Trauma Surg. 2009 Sep 1; 129(9):1233-8.

7. Shrestha R, Kandel M, Gupta HK, Shrestha SK, Dongol S, Hamal RR. A study of conservative management of tibial plateau fractures. JCMS Nepal. 2016; 12(1):5-9.

8. Catagni MA, Ottaviani G, Maggioni M. Treatment strategies for complex fractures of the tibial plateau with external circular fixation and limited internal fixation. J Trauma. 2007; 63(5):1043-53.

9. Raza H, Hashmi P, Abbas K, Hafeez K. Minimally invasive plate osteosynthesis for tibial plateau fractures. J Orthop Surg (Hong Kong) 2012;20 (1):42-7.

10. Kancherla NR, et al. Outcome of treatment of proximal tibial plateau fractures by minimally invasive percutaneous plating osteosynthesis technique. Int J Res Orthop. 2016; 2(3):132-7.

11. Reddy J. Praneeth Kumar, Nazeer B Shaikh, Arun HS, Kumar NM. Study of surgical management of proximal tibial fractures using locking compression plate. IJBAR. 2016; 07(03):123-7.

12. Rohra N, Suri HS, Gangrade K. Functional and Radiological Outcome of Schatzker Type V and VI Tibial Plateau Fracture Treatment with Dual Plates with minimum 3 years follow-up: A prospective study. J Clin Diagn Res. 2016;10 (5):RC05-RC10.

13. Prasad GT, Kumar TS, Kumar RK, Murthy GK, Sundaram N. Functional outcome of Schatzker type $\mathrm{V}$ and $\mathrm{VI}$ tibial plateau fractures treated with dual plates. Indian J Orthop. 2013;47(2):188-94.

14. Zhang Y, Fan DG, Ma BA, Sun SG. Treatment of complicated tibial plateau fractures with dual plating via a 2-incision technique. Orthopedics. 2012;35(3):e359-64.

15. Lubowitz JH, Elson WS, Guttmann D. Part II: arthroscopic treatment of tibial plateau fractures: intercondylar eminence avulsion fractures. Arthroscopy. 2005;21(1):86-92.

16. Boldin C, Fankhauser F, Hofer HP, Szyszkowitz $\mathrm{R}$. Three-year results of proximal tibia fractures treated with the LISS. Clin Orthop Relat Res. 2006 ; 445:222-9.

17. Madry H, van Dijk CN, Mueller-Gerbl M. The basic science of the subchondral bone. Knee Surg Sports Traumatol Arthrosc. 2010 Apr 1;18(4): 419-33.

18. Maru N, Mandaliya D, Parmar R. Two stage reconstruction protocol in management of high-energy proximal tibia fractures (Schatzker, type IV-VI). J Evolu Med Dent Sci. 2012; 1(4): 639-45.

AUTHOR AFFILIATION:

Dr. Shaikh Naeem ul Haq Assistant Professor of Orthopaedics Dow International Medical College/ Dow University of Health Sciences Karachi, Sindh-Pakistan.
Dr. Syed Salman Adil

Assistant Professor

Baqai Medical University/Hospital

Karachi, Sindh-Pakistan.
Dr. Raza Askari

(Corresponding Author)

Assistant Professor of Orthopaedics

DIMC-DUHS Karachi, Sindh-Pakistan. Email: dr_razaaskari@hotmail.com 